Tersedia online di: http://ejournal-balitbang.kkp.go.id/index.php/JP
e-mail:jurnalpari@gmail.com
JURNAL PARI
Volume 3 Nomor 2 Desember 2017
p-ISSN: 2502-0730
e-ISSN : 2549-0133

\title{
PENINGKATAN KOMPETENSI STAF PENGELOLA PERPUSTAKAAN DALAM UPAYA OPTIMALISASI PELAYANAN TERHADAP PEMUSTAKA
}

\author{
Improving the Competence of Library Management Staff to Optimize Services to the Users
}

\author{
KETUT MASIANI \\ Balai Besar Riset Budidaya Laut dan Penyuluh Perikanan (BBRBLPP) \\ Diterima tanggal : 8 Oktober 2017 diterima setelah perbaikan : 24 November 2017 disetujui terbit : 4 Desember 2017
}

\begin{abstract}
ABSTRAK
Pelayanan perpustakaan saat ini perlu terus ditingkatkan dalam upaya untuk optimalisasi pelayanan kepada pemustaka. Saat ini pemustaka dapat dikategorikan menjadi 2 generasi, yaitu Immigrant generation dan Digital natives. Pemustaka pada saat ini lebih cenderung bersifat digital native yang lebih mengutamakan teknologi informasi dalam melakukan penelusuran informasi. Kemudahan yang diberikan oleh media informasi yang ada di internet memunculkan perubahan karakter pemustaka dan mulai meninggalkan perpustakaan sebagai media sumber informasi. Pengkajian ini dilakukan untuk mengetahui kompetensi pustakawan yang dibutuhkan dalam pengelolaan perpustakaan serta upaya yang perlu dilakukan untuk mencapai kompetensi tersebut. Pengkajian ini menggunakan metode USG (Urgent, Seriousness, Growth). Data yang digunakan dalam pengkajian ini adalah data primer melalui kuesioner yang dibagikan ke beberapa ke peneliti, teknisi, karyawan administrasi serta mahasiswa yang sedang melakukan kegiatan di BBRBLPP. Hasil pengkajian menunjukkan bahwa yang paling dibutuhkan pengelola perpustakaan saat ini adalah kompetensi dan profesionalisme dalam bidang teknologi informasi dan komunikasi. Kompetensi dan profesionalisme ini dapat diperoleh melalui pelatihan di bidang kepustakawanan.
\end{abstract}

Kata Kunci : Pustakawan, kompetensi , layanan informasi, pemustaka

\section{ABSTRACT}

The current library services was need to be continuously improved in the effort of optimizing services to users. Currently users can be categorized into 2 generations, namely Immigrant generation and Digital natives. The presenters are more likely to be digital native who prioritize information technology in conducting information tracking. The ease given by the information media available on the internet led to changes in the character of the user and began to leave the library as a medium of information resources. This assessment is conducted to determine the competence of librarians needed in library management and efforts that need to be done to achieve these competencies. This assessment uses USG (Urgent, Seriousness, Growth) method. The data used in this assessment is primary data through questionnaires distributed to some researchers, technicians, administrative staff and students who are conducting activities at IMRAFE. The results showed that library managers are mostly required competence and professionalism in the field of information and communication technology. This Competence and professionalism can be obtained by librarianship training.

Keywords : Librarians, competencies, information services, library users

Korespondesi penulis:

$\mathrm{Br}$. Gondol. Desa Penyabangan,Kec.Gerokgak,Kab.

Buleleng-Bali, Telp: 03629227

Email :ktmasiani@gmail.com 


\section{PENDAHULUAN}

Perpustakaan merupakan salah satu institusi yang berfungsi sebagai sumber informasi dan memiliki peranan yang penting dalam pengelolaan segala jenis informasi. Perpustakaan adalah institusi pengelola koleksi karya tulis, karya cetak, dan atau karya rekam secara profesional dengan sistem yang baku guna memenuhi kebutuhan pendidikan, penelitian, pelestarian, informasi, dan rekreasi para pemustaka (Anonim(a), 2007). Oleh karena itu diharapkan dapat memberikan pelayanan yang optimal dengan menyediakan segala kebutuhan informasi pemustaka.

Perpustakaan dituntut untuk mampu berkembang seiring dengan perkembangan teknologi informasi dan tuntutan pemustaka. Perpustakaan perlu melakukan perubahanperubahan dalam upaya untuk lebih mengoptimalkan tugas dan fungsinya. Perubahan-perubahan tersebut dapat berkaitan dengan: pemustaka, layanan, fasilitas teknologi informasi, sumber daya manusia/pustakawan, maupun fungsi dan nilai tambah (Fatmawati, 2012). Generasi pemustaka dapat dikelompokkan berdasarkan pemanfaatan teknologi informasi yaitu immigrant generation dan digital native generation (Prensky, 2001). Immigrant generation yaitu generasi yang mengenal dan menggunakan teknologi informasi setelah dewasa, sedangkan digital native/net generation yaitu generasi yang semenjak lahir/kecil sudah mengenal dan menggunakan teknologi informasi. Salah satu ciri immigrant generation yaitu mengutamakan menelusuri informasi secara manual melalui buku cetak kemudian baru beralih ke internet. Digital native generation mengutamakan penggunaan media internet dalam melakukan penelusuran informasi serta selalu terhubung dengan dunia luar melalui internet, berinteraksi melalui chatting, serta menginginkan kecepatan (Wulandari, 2011). Generasi ini juga memiliki harapan tinggi terhadap penggunaan teknologi untuk mendukung proses belajar (Roberts, 2005).

Untuk dapat memberikan pelayanan yang optimal maka perpustakaan perlu menjembatani kedua generasi tersebut. Perpustakaan harus mampu menyediakan media informasi untuk pengguna yang mengutamakan penelusuran manual dan juga pemustaka mengutamakan penelusuran melalui internet. Perpustakaan harus bersifat fleksibel, mampu melakukan perubahanperubahan sesuai dengan perkembangan yang terjadi. Perubahan dapat disebabkan oleh beberapa faktor yaitu inovasi (penemuan baru/ perubahan), invensi (penemuan baru), adaptasi (penyesuaian secara sosial dan budaya) serta adopsi (penggunaan dari penemuan baru/teknologi (Sutherland dalam Hastarini, 2007). Kemampuan untuk berkembang dan melakukan perubahan akan mampu mempertahankan perpustakaan dalam melakukan tugas dan fungsinya sehingga tidak ditinggalkan oleh penggunanya. Hal ini sesuai dengan hukum ilmu perpustakaan bahwa "The library is a growing organism," but "the library must grow its market or die."(Ranganathan dalam Fister, 2012). Dari pernyataan ini dapat dijelaskan bahwa perpustakaan merupakan lembaga yang terus menerus berkembang untuk mampu memenuhi kebutuhan dan tuntutan pemustaka sehingga tidak kehilangan peran dan fungsinya atau ditinggalkan oleh pemustakanya.

Agar sesuai dengan perkembangan teknologi informasi, dibutuhkan pustakawan yang memiliki kemampuan dibidang teknologi informasi serta memiliki kompetensi dalam bidang perpustakaan.

\section{DISKRIPSI PERMASALAHAN}

Pada saat ini pencarian informasi dapat dilakukan secara mudah melalui media internet sehingga dapat diperoleh beragam sumber informasi. Kemunculan sumber informasi ini merupakan tantangan yang harus dihadapi oleh perpustakaan dalam upaya untuk mempertahankan peran dan fungsinya sebagai sumber informasi.

Pemanfaatan perpustakaan sebagai sumber informasi semakin menurun sehingga perlu dilakukan perubahan baik dalam sumber daya koleksinya maupun dalam bidang sumberdaya manuasi/pengelolanya.

Karakter pemustaka saat ini cenderung bersifat digital native yang lebih mengutamakan pemanfaatan internetdalam penelusuran informasi. Untuk melakukan perubahan dan pengembangan perpustakaan dengan pemanfaatan teknologi informasi dibutuhkan pengelola perpustakaan/ pustakawan yang memiliki ilmu pengetahuan, kompetensi dan profesionalisme kerja yang berdaya saing terutama dalam bidang teknologi informasi dan komunikasi. 


\section{Perubahan Karakter Pengguna.}

Beragamnya informasi serta kecepatan dan kemudahan yang disediakan oleh sumber-sumber infomasi di internet menyebabkan perpustakaan yang dulunya merupakan salah satu sumber informasi kini semakin ditinggalkan. Pemustaka lebih cenderung untuk memanfaatkan teknologi informasi di internet. Pemustaka hanya menjadikan perpustakaan sebagai pilihan kedua sumber informasi. Hal ini tidak dapat dipungkiri karena pemustaka lebih mudah memperoleh informasi di media internet, informasi yang tersedia juga sangat beragam sehingga pemustaka dapat memilih informasi yang ada sesuai dengan kebutuhannya. Teknologi informasi ini juga menyajikan informasiinformasi terbaru secara cepat dan luas. Hal ini sangat membantu pemustaka /pencari informasi untuk dapat memperoleh informasi yang dibutuhkannya secara cepat dan mudah. Hal ini sesuai dengan karakter pemustaka saat ini yaitu menginginkan informasi yang terbaru yang akurat, mengharapkan layanan yang nyaman, didesain secara handal, dan layanan yang berkualitas tinggi (Laughlin dalam Fatmawati, 2014). Perubahan karakter pemustaka tersebut didorong oleh teknologi, perilaku pemustaka, profil angkatan kerja dan angkatan kerja antar generasi (Saw \& Todd, 2007). Pengelola perpustakaan harus cepat mengatasi permasalahan ini dengan melakukan perubahan sesuai dengan tuntutan pemustaka sehingga tujuan pelayanan pemustaka untuk memanfaatkan koleksi perpustakaan semaksimal mungkin (Lasa, 1994) terpenuhi serta mampu menawarkan semua bentuk koleksi yang dimiliki perpustakaan kepada pemakai yang datang ke perpustakaan dan meminta informasi yang dibutuhkannya (Darmono, 2001).

Karakter pemustaka saat ini cenderung bersifat digital native yang lebih mengutamakan pemanfaataninternetdalampenelusuraninformasi. Untuk melakukan perubahan dan pengembangan perpustakaan dengan pemanfaatan teknologi informasi dibutuhkan pengelola perpustakaan/ pustakawan yang memiliki ilmu pengetahuan, kompetensi dan profesionalisme kerja yang berdaya saing terutama dalam bidang teknologi informasi dan komunikasi.

\section{METODE}

\section{Sumber Data}

Dalam penulisan ini sumber data yang digunakan terdiri dari:

\section{a. Data Primer}

Data primer yang digunakan dalam penulisan ini diperoleh dari data kuesioner atau angket yang disebarkan kepada peneliti, teknisi, mahasiswa dan karyawan bagian administrasi serta pengelola perpustakaan.

\section{b. Data sekunder}

Data sekunder merupakan data yang diperoleh dari sumber yang sudah ada. Data sekunder dalam penulisan ini diperoleh dari buku, artikel, dan sumber informasi lain yang terkait dengan permasalahan kompetensi pustakawan di situs internet.

\section{Teknik Pengumpulan Data}

Pengumpulan data merupakan proses dan faktor yang penting dalam melakukan pengkajian atau penelitian yang meliputi bagaimana cara untuk mengumpulkan data dan alat yang digunakan untuk mengumpulkan data (Harnovinsah, 2014). Teknik pengumpulan data yang digunakan dalam penelitian ini adalah metode survey dengan penyebaran kuesioner atau angket kepada peneliti, teknisi, mahasiswa dan karyawan bagian administrasi serta pengelola perpustakaan.

\section{Teknik Analisis Data}

Menurut Patton dalam Moleong (2002) analisis data adalah proses mengatur urutan data, mengorganisasikanya ke dalam suatu pola, kategori, dan satuan uraian dasar. Analisis data adalah rangkaian kegiatan penelaahan, pengelompokan, sitematisasi, penafsiran dan verifikasi data agar sebuah fenomena memiliki nilai sosial, akademis, dan ilmiah. Dalam pengkajian ini data dianalisis menggunakan metode USG (Urgent, Seriousness, Growth). Urgency (kegawatan), yakni mengukur besarnya dampak yang ditimbulkan pada unsur-unsur dalam organisasi. Seriousness (kemendesakan), yakni banyaknya waktu yang tersedia untuk menangani suatu masalah serta Growth (pertumbuhan), perkiraan akan bertambah buruknya suatu masalah di masa yang akan datang dibandingkan dengan kondisi sekarang. 
Berdasarkan teori Kepner dan Tragoe (1981) dalam membandingkan suatu permasalahan ada tiga aspek yaitu:

1. Bagaimana gawatnya masalah dilihat dari pengaruhnya sekarang ini terhadap produktivitas, orang, dan / atau sumber dana dan daya?

2. Bagaimana mendesaknya dilihat dari waktu yang tersedia?

3. Bagaimanakah perkiraan yang terbaik mengenai kemungkinan berkembangnya masalah

Skala pada masing-masing kriteria (skala likert ) pada umumnya adalah dimulai dari angka 1(satu) sampai dengan angka 5 (lima), (Anonim (b), 2008). Penilaian pada kuesioner untuk penulisan ini menggunakan skala likert yaitu dari nilai 1 sampai dengan 5 dengan kategori sebagai berikut:

a) Nilai 5 menunjukkan masalah yang sangat mendesak.

b) Nilai 4 menunjukkan masalah yang mendesak

c) Nilai 3 menunjukkan masalah yang cukup mendesak

d) Nilai 2 menunjukkan masalah yang kurang mendesak

e) Nilai 1 menunjukkan masalah yang sangat kurang mendesak.

\section{Penyajian Data}

Data yang dihasilkan dikumpulkan kemudian dijumlahkan berdasarkan kelompoknya, kemudian disajikan dalam bentuk tabel dan grafik.

\section{Penarikan Kesimpulan dan Verifikasi}

Penarikan kesimpulan merupakan proses perumusan makna dari hasil pengkajian yang telah dilakukan berdasarkan data-data yang diperoleh atau penggambaran makna dari data yang ditampilkan.

\section{PEMBAHASAN}

\section{Peningkatan Kompetensi Pustakawan}

Kompetensi merupakan kemampuan seseorang yang mencakup pengetahuan, keterampilan dan sikap kerja yang dapat teramati dalam menyelesaikan pekerjaanatautugassesuaidengan standar kinerja yang diterapkan (Basuki, 2014). Pada saat ini kompetensi dan profesionalisme pustakawan sangat dibutuhkan untuk membangun perpustakaan yang berdaya saing. Pustakawan yang berkompetensi yaitu seseorang yang mampu memahami tugasnya, memiliki motivasi, memiliki pengetahuan dan keterampilan, kepercayaan diri dalam melaksanakan tugas serta mampu bersikap atas dasar pekerjaan yang menjadi tanggungjawabnya (Basuki, 2014). Peningkatan kompetensi ini diharapkan dapat memperkuat profesionalisme kerja pustakawan.

Menurut (Basuki, 2014) untuk menjadi pustakawan yang berkompeten dan memiliki daya saing harus memiliki beberapa kemampuan dan pengetahuan diantaranya yaitu:

1. Kemampuan dalam bidang teknologi informasi dan komunikasi

2. Kemampuan dalam berkomunikasi dan berbahasa

3. Kemampuan dalam literasi informasi

4. Kemampuan dan keahlian dalam pelayanan teknis dan pengguna

5. Pemikiran yang inovatif dan kreatif kemampuan untuk bekerja sama

6. Mental yang kuat dan pengakuan diri Penglola yang berkompeten mampu memberikan kepuasan kepada pemustaka dan mampu memenuhi informasi yang dibutuhkan pemustaka yang dipengaruhi oleh:

1. Kinerja pelayanan

2. Respon terhadap keinginan pemustaka

3. Kompetensi petugas

4. Pengaksesan mudah, murah, tepat dan cepat

5. Kualitas koleksi

6. Kesediaan alat temu kembali

7. Waktu Layanan (Lasa dalam Rakib, 2013)

\section{Strategi Peningkatan Kompetensi}

Peningkatan kompetensi merupakan tindakan yang dilakukan dalam upaya memperoleh dan menambah ilmu pengetahuan, keterampilan dan keahlian dalam bidangnya kegiatannya. Kompetensi seorang pustakawan dapat diperoleh melalui kegiatan sehari-hari dan juga dengan mengoptimalkan potensi dirinya. Ada beberapa strategi/ tindakan yang diperlukan untuk mencapai tujuan kompetensi yaitu:

1. Tanggap

2. Berpikir kritis dan analisis

3. Memiliki dasar pengetahuan dan kemampuan penerapan pengetahuan 
4. Mengikuti perubahan sekitarnya/lingkungan

5. Mampu berkomunikasi

6. Mampu bekerjasama

7. Menjalin hubungan dengan pengguna, kolega, profesi ,instansi luar perpustakaan

8. Melakukan evaluasi dan penilaian sumber daya dan jasa

9. Memahami kebutuhan pengguna

10. Melakukan layanan informasi

11. Penyedia layanan informasi (Whitlatch, 2013).

\section{Sertifikasi Kompetensi}

Untuk meningkatkan kompetensi dan mendapat pengakuan terhadap kompetensi yang dimilikinya, seorang pustakawan diwajibkan lulus uji kompetensi sertifikasi yang ditetapkan oleh Standar Kompetensi Kerja Nasional Indonesia (SKKNI) (Anonim ${ }^{(b)}$, 2012). Tiga jenis kompetensi kerja yang ditetapkan pada SKKNI tersebut meliputi:

1. Kompetensi Umum (Pengetahuan) yaitu kompetensi dasar yang menyangkut pengetahuan dasar yang dimiliki seorang pustakawan dalam melaksanakan tugasnya

2. Kompetensi Inti (Keterampilan) yaitu menyangkuttentang keterampilan pustakawan

3. Kompetisi Khusus (Sikap Kerja) yaitu profesionalisme pustakawan

\section{Pustakawan Yang Berdaya Saing}

Dalam perkembangan teknologi informasi ini seorang pustakawan dituntut untuk dapat bersaing dan memiliki kesejajaran pengetahuan dengan pengelola informasi lain yang saat ini telah memanfaakan teknologi informasi. Seorang pustakawan juga dituntut untuk memilki kemapuan dalam penelusuran, pengelolaan dan penyebaran informasi. Pustakawan sudah sepatutnya mengetahui informasi yang terbaru, yang sedang hangat dibicarakan serta mampu menyebarkan informasi tersebut kepada pemustaka yang membutuhkannya. Selain sebagai sumber informasi dan sebagai pelayanan informasi seorang pustakawan juga dapat menjadi:

1. Agen perubahan

2. Bank data

3. Konsultan informasi
Dengan kemampuan ini maka seorang pustakawan akan mampu bersaing dan menjadi seorang yang berkompeten dalam memberikan pelayanan terhadap pemustaka.

\section{KESIMPULAN}

Seiring perkembangan teknologi informasi serta persaingan sumber informasi, perpustakaan harus dapat berdaya saing dengan sumber informasi lain dengan mengembangkan perpustakaan sesuai dengan perkembangan teknologi informasi, kebutuhan dan tuntutan pemustaka.

Peningkatan kualitas, kompetensi dan profesionalisme pustakawan saat sangat perlu dilakukan untuk dapat melakukan perubahan dan mengembangkan perpustakaan sesuai dengan teknologi yang ada.

Kompetensi dan profesionalisme ini dapat diperoleh dengan pelatihan, peningkatan mutu pendidikan perpustakaan dan uji sertifikasi kompetensi.

Dengan keahlian ini maka pustakawan akan dapat mengembangkan perpustakaan sesuai dengan kebutuhan pemustaka serta akan membentuk perpustakaan yang berdaya saing sehingga mampu memberikan layanan yang optimal kepada pemustaka.

\section{SARAN}

Pengelola perpustakaan harus lebih meningkatkan kompetensi dan profesionalisme di bidang perpustakaan dan teknologi informasi.

\section{DAFTAR PUSTAKA}

-------. Undang-Undang Nomor 43 Tahun 2007 tentang Perpustakaan.

Keputusan Menteri Tenaga Kerja dan Transmigrasi Republik Indonesia Nomor 83 Tahun 2012 tentang penetapan rancangan standar kompetensi kerja nasional Indonesia sektor jasa kemasyarakatan, sosial budaya, hiburan, dan perorangan lainnya bidang perpustakaan menjadi standar kompetensi kerja nasional Indonesia. - Jakarta: Perpustakaan Nasional RI

Basuki S. 2014. Sertifikasi Pustakawan, 
https://sulistyobasuki.wordpress. com/2014/07/05/sertifikasi-pustakawan/. Diakses tanggal 8 Agustus 2015

Darmono. 2001. Manajemen dan Tata Perpustakaan Sekolah, Cet. I, Jakarta: Gramedia Widiasarana Indonesia. Pp; 134

Fatmawati, E. 2012. Trend terkait m-library untuk Perpustakaan masa depan. Visi Pustaka Vol. 14, No. 3, Desember 2012.pp: 36-45

Fatmawati, E. 2014. Rekonstruksi Peran Pustakawan Perguruan Tinggi Untuk Membangun Perpustakaan Ideal. http:// pustaka.uns.ac.id/?menu=news\&option=det ail\&nid=411. Diakses tanggal 9 Oktober 2015

Fister, B. 2012. Librarians as Agents of Change. http://homepages.gac.edu/ fister/ACRLORWA. pdf. Diakses tanggal 13 Agustus 2015

Hastarini,S.W. 2007. Dampak Perpustakaan Terhadap Perubahan Sosial Masyarakat. Mimbar Pustaka Jatim No 01/Th./januariMaret 2007. p.16-17

https://www.scribd.com/doc/6592742/ Perubahan-Sosial. Diakses tanggal 9 Oktober 2015

Lasa, HS, ,1994. Jenis-jenis Pelayanan Informasi Perpustakaan. Gadjah Mada University Press, Yogyakarta. pp: 213

Prensky, M. 2001. Digital Natives, Digital Immigrants. NCB UniversityPress. https://edorigami.wikispaces.com/file/view/ prensky+-+digital+natives+and+immigran ts+1.pdf. Diakses tanggal 9 Oktober 2015

Rakib, F.A. 2013. Kepuasan Pemustaka Terhadap Layanan Perpustakaan Keliling Terapung (Studi Kasus Di Kota Ternate). Journal Volume II. No. 4. Tahun 2013.Pp: 4: http://www.ejournal.unsrat.ac.id/index. php/actadiurna/article/download/2977/2523. Diakses tanggal 8 Oktober 2015

Roberts, G. R. 2005. Technology and Learning Expectations of the Net Generation. . Educating the Net Generation (pp. 32-38). Louisville. 2005.

https://net.educause.edu/ir/library/pdf/pub7101. pdf. diakses tanggal 13 Agustus 2015

Saw \& Todd. 2007. Library 3.0: Where Art Our Skills?.PaperOnWorld LibraryAnd Information Congress: 73rd Ifla General Conference And Council, 19-23 August,Durban, South Africa. http://Archive.Ifla.Org/lv/lfla73/ Papers/151Saw_Todd-En.Pdf, Akses 13 Agustus 2015.

Whitlatch, J. B. 2003. Professional Competencies for Reference and User Services Librarians.

http://www.ala.org/rusa/resources/guidelines/ professional tanggal 10 Oktober 2015

Wulandari, D. 2011. Mengembangkan Perpustakaan Sejalan Dengan Kebutuhan Net Generation. Visi Pustaka, 13(2), 16-24. 